\title{
ECONOMIC RISK AND POLITICAL RISK IN FISCAL UNIONS
}

\author{
Alberto Alesina \\ Roberto Perotti
}

Working Paper No. 4992

\section{NATIONAL BUREAU OF ECONOMIC RESEARCH 1050 Massachusetts Avenue \\ Cambridge, MA 02138 \\ January 1995}

This research was supported by NSF grant No. SBR-9414719. We thank Jeffrey Sachs for useful comments. This paper is part of NBER's research programs in International Finance and Macroeconomics and Public Economics. Any opinions expressed are those of the authors and not those of the National Bureau of Economic Research.

C) 1994 by Alberto Alesina and Roberto Perotti. All rights reserved. Short sections of text, not to exceed two paragraphs, may be quoted without explicit permission provided that full credit, including $(\odot$ notice, is given to the source. 


\title{
ECONOMIC RISK AND POLITICAL RISK IN FISCAL UNIONS
}

\begin{abstract}
A fiscal program that redistributes income from rich to poor individuals indirectly redistributes tax revenues from regions hit by a favorable shock to regions hit by an unfavorable one. Centralized fiscal redistribution has therefore been advocated as a way to insure individuals against region-specific shocks. In this paper, we argue that a centralized fiscal policy, while reducing the uncertainty on the tax base, creates uncertainty on the tax rate. This occurs because regions hit by different shocks have contrasting interests on the choice of the policy instrument. Using a simple model with two regions and linear taxes, we show that the higher uncertainty on the policy instrument might more than offset the lower uncertainty on the tax base, thus making a majority of agents in each region worse off in a centralized regime.

The model is a special case of a more general idea. Heterogeneous entities can reap numerous advantages from integration: mutual insurance (on which we focus), economies of scale, more bargaining power are only a few of them. However, at the same time the same process of integration can increase the unpredictability of any endogenous policy, because more diverse entities participate in the decision-making process, and therefore the opportunities for disagreement increase. In principle, this second effect might offset the advantages of integration.
\end{abstract}

\author{
Alberto Alesina \\ Department of Economics \\ Harvard University \\ Cambridge, MA 02138 \\ and NBER
}

\author{
Roberto Perotti \\ Department of Economics \\ Columbia University \\ 420 West 118th Street, 10th Floor \\ New York, NY 10027
}




\section{Introduction.}

Several countries around the world are breaking up (e.g., the former Soviet Union), and in others regional movements are becoming more vocal in demanding more autonomy (e.g., Italy, Spain); at the same time, several Western European countries are integrating in a supernational community. Fiscal policy issues, and, in particular, the level of centralization of fiscal decisions are often important considerations in the formation or collapse of political jurisdictions or of federations of regions and countries. ${ }^{1}$

A long tradition in public finance argues that a centralized fiscal system can reach more efficient outcomes by better internalizing the numerous externalities associated with both the expenditure and the revenue sides of fiscal policy, particularly when factors are mobile. This line of argument applies to both the provision of public goods (Gordon (1983)) and to redistributive fiscal policy (Pauli (1973), Ladd and Doolittle (1982), Brown and Oates (1987)). A counterargument to this conclusion is developed in Perotti (1993), who shows that in the presence of differences in, say, labor markets or the administration of fiscal policy, centralized redistribution can lead to a more inefficient allocation of resources.

A second argument in favor of centralized fiscal policy is based on the insurance properties of redistribution. When different countries are hit by idiosyncratic shocks, they can stabilize the tax base by running a common fiscal policy: the taxable income in the countries hit by a negative shock decreases, but it increases in the countries hit by a positive shock. Thus, for a given tax rate the revenues available for redistribution are more stable in a centralized system. It follows that a centralized system of redistribution, that encompasses several countries, can better stabilize post-tax incomes and insure individuals against country-specific shocks (see Persson and Tabellini (1992) and Sachs and Sala-I-Martin (1992)). The mutual insurance argument for a centralized fiscal regime is a powerful one. However, in our view it overlooks the implications of an uncontroversial, but important, fact: fiscal policy is endogenous, and is decided through processes that, like voting, aggregate the preferences of diverse individuals.

The basic idea of this paper is that in a centralized regime more individuals from more countries participate in the decision-making process; consequently, the diversity of the decision-makers increases, and this is reflected in more, rather than less, uncertainty about the policy instrument. In turn, this might lead to more, rather than less, instability in income and consumption. In other words, we emphasize a trade-off: large jurisdictions can

\footnotetext{
${ }^{1}$ The words " country" and "region" can be used interchangeably in this paper. The reference to "countries" is more natural in a discussion of issues concerning the process of European integration. The reference to "regions" is more appropriate in the context of the debate on fiscal policy within individual countries, like, for example, in Italy. From now on, and only for brevity's sake, we will refer to the basic jurisdiction in our model as a "country".
} 
achieve the benefits of centralized redistribution, but these benefits are offset (partially or completely) by the increase in the diversity and, thus, in potential conflicts of interests among the citizens of larger jusridictions. ${ }^{2}$

We illustrate this idea using a very simple two-country model. The two countries can insure each other by running a common redistributive fiscal policy because their shocks are not perfectly correlated, so that their combined tax bases are less variable than their individual tax bases. Therefore, the subsidy that can be financed with a given tax rate is also less variable in a centralized regime. However, when the tax rate is endogenous, we show that a centralized regime creates uncertainty about the tax rate, even though it reduces the uncertainty about the tax base. Thus, when the endogeneity of fiscal policy is taken into consideration, centralizing redistribution leads to more uncertainty about the policy instrument. In turn, this might well lead to a higher, rather than lower, variability in the post-tax income of a majority of the individuals in the economy. We also show that the variability of consumption increases, for a majority of agents, with the polarization of income distribution (and, therefore, of preferences) within each country. Thus, the insurance effect of centralization prevails when member countries are relatively homogeneous, generating a union with little polarization of preferences.

Moreover, although we have cast this paper in the framework of redistributive fiscal policy, we think that its implications are more general. The basic idea is that heterogeneous entities can reap numerous advantages from integration: mutual insurance (on which we focus), economies of scale, more bargaining power are only a few of them. However, at the same time the same process of integration can increase the unpredictability of any endogenous policy, because more diverse entities participate in the decision-making process, and therefore the opportunities for disagreement increase. In principle, this second effect might offset the advantages of integration.

The outline of the paper is as follows. The model is described in the next section. In section 3 , we characterize the equilibrium in the two regimes, while in section 4 we define rigorously the two crucial notions of economic risk and political risk. In the following two sections we use these notions to compare the two regimes under different assumptions about the distributions of endowments; in particular, section 5 fully solves a more specific example, while section 6 analyses the more general case with the help of numerical solutions. Section 7 concludes.

\footnotetext{
${ }^{2}$ Alesina and Spolaore (1994) discuss the endogenous formation of countries based upon a similar tradeoff for the case of public good provision.
} 


\section{The model.}

2.1 Technology, preferences and endowments.

The model has one period and two countries, 1 and 2 . In each country a single factor, labor, can produce a single good with a constant returns to scale production function: $y=n$, where $y$ denotes units of output and $n$ denotes units of labor. The price of the good is normalized at 1 .

The per capita endowments of the two countries are the same, and equal to $\bar{n}$. We adopt this assumption in order to better isolate the problem we want to address in this paper, that of the trade-off between economic and political uncertainty with fiscal policies that redistribute income among income classes. If we allowed for different per capita incomes between the two countries, a centralized system that redistributes income across income classes would at the same time systematically transfer income between countries, from the richer one to the poorer one. If the difference in per capita endowments is large enough, the latter type of redistribution becomes disproportionately important, overshadowing the former type of redistribution, upon which we want to focus.

Individuals can belong to one of three income classes, $A, B$ and $C$, characterized by endowments of labor $n_{A}, n_{B}$ and $n_{C}$ respectively. Thus, the endowment of labor of an individual of, say, class $A$ is the same in the two countries. We make this assumption only to simplify the analytical solution of the model, but our conclusions do not hinge crucially on it. The assumption of three income classes too is made only for convenience: its advantage is that it allows us to characterize the equilibrium as a function of two parameters, $n_{A}$ and $n_{B}$ (note that, given the per-capita income and the sizes of each class, $n_{C}$ is determined residually). Conceptually, the model can be easily generalized to the case of $\mathrm{N}$ classes, where $\mathrm{N}$ can be arbitrarily large, at the cost of a more frequent recourse to numerical solutions. ${ }^{3}$

Letting $p_{i, j}$ represent the fraction of the population in the income class $i$ in country $j$, we make the following assumptions on the distribution of endowments in the two countries:

(i) $p_{i, j}<.5 \forall i, j$;

(ii) $n_{A}<n_{B}<\bar{n}<n_{C}$.

\footnotetext{
${ }^{3}$ It is more difficult to find an analytical solution when the distribution of endowments is continuous. The reason is that, as we show below, the tax rate in the centralized regime is in general the ratio of two random variables that are functions of the median and the average of a function of the original distribution. All these functions are extremely difficult to determine analytically, and we have not been able to find a distribution that lends itself to an analytical solution in this context.
} 
Assumption (i) implies that no income class has, by itself, the majority of votes: this avoids trivial voting equilibria. In what follows, only for simplicity we further assume that the three income classes are of equal size: thus, we assume that in both countries each class has exactly $1 / 3$ of the total population: $p_{i, j}=1 / 3 \forall i, j$. This assumption too is by no means necessary; it is only useful to simplify the analysis and to concentrate on the more substantive issues of the model. ${ }^{4}$ Together with the first, assumption (ii) implies that in each country the median voter is a member of the income class $B$; furthermore, the distribution of endowments is skewed to the right, i.e. the median endowment is below the average. This is consistent with the observed shape of practically all income distributions in the world. Besides being empirically valid, this assumption also implies that, given the fiscal system that we specify below, the median voter votes for a positive tax rate. This condition avoids a trivial equilibrium, with a tax rate equal to 0 in all states of the world.

The only asymmetry between the two countries is in the total mass of their population: the total mass is $1+\delta$ in country 1 and 1 in country 2 , with $\delta$ being arbitrarily small. If the two countries had the same population, in this perfectly symmetric model the voting equilibria in the centralized regime - where all individuals of the two countries vote together - often would result in a perfect tie between two proposals. Our assumption then is a very convenient way to break the ties in the voting equilibria. In the absence of this assumption, the outcome would depend on the rules one assumes to break the ties: for instance, the average of the two tax rates, the status quo ( 0 tax rate), etc. However, as we showed in a previous version of this paper, even in this case our results are robust to alternative assumptions about how ties are broken.

An individual of type $i$ in country $j$ has a concave utility function $U\left(C_{i, j}\right)$. We illustrate our model using two specific functional forms for $U(\cdot)$, the quadratic and the constant relative risk aversion utility functions. The former case allows us to provide an analytic solution of the model. The latter case allows us to provide a more general treatment and to study the role of risk aversion, but requires numerical simulations.

Finally, individuals are not mobile across countries. We make this assumption in order to avoid strategic issues in the choice of the tax rate and problems of tax competition, that are not the focus of our analysis.

\subsection{The productivity shock.}

The only source of uncertainty in the model is a country-specific productivity shock, $\epsilon_{j}$, $j=1,2$. The shocks in the two countries have 0 mean, the same variance $\sigma_{\epsilon}^{2}$, and covariance $\sigma_{\epsilon_{1} \epsilon_{2}}$. The shock is multiplicative and affects all agents in a country in the same proportion.

\footnotetext{
${ }^{4}$ In fact, in a previous version of this paper we develop a case with different class sizes.
} 
Thus, when country $j$ is hit by the shock $\epsilon_{j}$, an individual of type $i$ effectively provides $n_{i}\left(1+\epsilon_{j}\right)$ units of labor. We refer to the quantity $n_{i}$ as the endowment of an individual of type $i$ in country $j$, while the quantity $n_{i}\left(1+\epsilon_{j}\right)$ denotes his income. Therefore, the realized average income of country $j$ is $\bar{n}\left(1+\epsilon_{j}\right)$.

\subsection{Fiscal policy.}

Fiscal policy consists of a program that redistributes income across individuals, via a proportional income tax whose proceeds are redistributed lump-sum to all individuals. ${ }^{5}$ The tax rate is decided by majority voting after the shock occurs. Note that the timing here is important: since the two countries are identical ex-ante, voting before the shock would generate uninteresting results.

Moreover, the timing we have chosen arises naturally in our model. The reason is that the shock we have in mind is a permanent productivity shock; if the shock were temporary and serially uncorrelated, in a dynamic version of this model a country could smooth out most of its effects by lending or borrowing on the world capital market. Issues of mutual insurance therefore are particularly important if the shock is permanent; but then, the resulting change in the equilibrium tax rate must be interpreted as a structural change in fiscal policy induced by the permanent shock.

Taxation is distortionary. We model the distortions caused by taxation in a stylized way: we assume that when the total taxable income is $X$ and the tax rate is $t$, the total tax revenues that can be redistributed are $\left(t-\frac{1}{2} t^{2}\right) X$ : the quantity $\frac{1}{2} t^{2} X$ is wasted in the process of collecting taxes or redistributing them. We can think of these costs as the distortionary effects of income taxes on labor supply. As we show later, this assumption implies that the tax rate preferred by each individual is a continuous function of his endowment. Without this assumption, the equilibrium tax rate in the model would exhibit a discontinuous behavior, with an equilibrium tax rate of either 0 or 1 , depending on whether the endowment of the median voter is above or below the average endowment, respectively.

We are interested in studying the trade-off between two aspects of redistributive fiscal policy: its role in creating uncertainty due to the endogeneity of the policy instrument, and its role in decreasing the uncertainty of the economic environment by sharing risk among individuals and countries.

The first effect of redistributive fiscal policy, the uncertainty caused by the endogeneity of the tax rate, arises naturally in this framework because, as we show below, the tax rate chosen by the median voter can be affected by the shock. In this model with no individual-

\footnotetext{
${ }^{5}$ This is a standard formalization of a progressive tax and subsidy system: see e.g. Meltzer and Richard (1981). With more nonlinear tax systems, it is not always possible to find a stable majority in the voting process, as shown by Romer (1975) and Roberts (1977).
} 
specific shock, the second role of redistributive fiscal policy, sharing risk, can be fulfilled by a centralized fiscal system. Whenever the two shocks are not perfectly positively correlated, a supernational fiscal policy that combines the tax bases of the two countries and redistributes income from rich individuals to poor individuals indirectly redistributes some income from the "lucky" to the "unlucky" country, thus fulfilling also an insurance role. It should also be clear that, since there is no individual-specific risk, a redistributive scheme cannot have any insurance property if carried out at the national level. Thus, to study the insurance properties of fiscal policy we consider two alternative fiscal policy regimes:

\section{Definition 1.}

Decentralized fiscal policy: each country runs its own program, by taxing its own citizens and redistributing the proceeds lump-sum to them. In each country, the tax rate is chosen by majority voting.

Centralized fiscal policy: the same tax rate applies to all the individuals of the two countries. The proceeds from taxation in the two countries are pooled and redistributed lumpsum to all individuals in the two countries. The common tax rate is decided by majority voting among the citizens of the two countries, voting together.

\subsection{Absence of private insurance and of direct transfers.}

We have assumed that any insurance against fluctuations in income occurs through the same fiscal program that redistributes income. In principle, however, individuals could insure themselves privately, without the intermediation of a program that redistributes income across different groups. Alternatively, the two countries could agree on a system of direct transfers from the "lucky" country to the "unlucky" one.

In practice, there are a host of well-known reasons - from adverse selection to imperfect monitoring of outcomes - why private insurance schemes might not be viable. Similarly, it might be difficult for two governments to implement a direct system of mutual insurance through inter-country transfers. After the shock is realized, clearly the lucky country stands to lose from the implementation of the agreement, and it has strong incentives to renegotiate it.

Clearly, the same problem arises even in the context of a centralized program of interpersonal redistribution of income. By its nature, this program also redistributes income from the lucky country to the unlucky one. However, because it also entails some interpersonal redistribution of resources, it might well obtain the support of a majority of agents even in the country that, on net, loses resources to the other country. ${ }^{6}$

${ }^{6}$ See Persson and Tabellini (1992) for an analysis of the interaction between interpersonal redistribution 
Thus, for a variety of reasons, public redistributive programs are widely regarded as having insurance properties against individual and country-specific shocks over and above whatever is provided by the market or other government insurance schemes. For instance, Sachs and Sala-I-Martin (1992) calculate that in the U.S. states, because of the progressivity of the income tax, disposable income decreases by 56 to 65 cents when state GDP falls by 1 dollar.

\section{Equilibrium fiscal policy.}

The disposable income (which is equal to consumption in this static model) of an individual of type $i$ in country $j$ in the decentralized regime is:

$$
C_{i, j}^{d}=\left(1-t^{d}\right) n_{i}\left(1+\epsilon_{j}\right)+\left(t^{d}-\frac{1}{2} t^{d^{2}}\right) \bar{n}\left(1+\epsilon_{j}\right)
$$

where the superscript $d$ stands for "decentralized". In (1), the first term, $n_{i}\left(1+\epsilon_{j}\right)\left(1-t^{d}\right)$, is the "after-tax earned income". The second term in (1) is the "subsidy" received by the same individual, i.e. the lump-sum transfer paid to each individual out of the tax revenues collected by the government. In fact, the average tax revenue is $t^{d} \bar{n}\left(1+\epsilon_{j}\right)$ and a fraction $\frac{1}{2} t^{d^{2}} \bar{n}\left(1+\epsilon_{j}\right)$ is lost in the collection or redistribution process.

The disposable income and consumption level of an individual of type $i$ in country $j$ in the centralized regime is equal to

$$
C_{i, j}^{c}=\left(1-t^{c}\right) n_{i}\left(1+\epsilon_{j}\right)+\left(t^{c}-\frac{1}{2} t^{c^{2}}\right) \bar{n}\left(1+\frac{\epsilon_{1}+\epsilon_{2}}{2}\right)
$$

where the superscript $c$ stands for "centralized". Expression (2) has the same interpretation as (1), except that now the tax base from which the subsidies are drawn is $\bar{n}\left(2+\epsilon_{1}+\epsilon_{2}\right)$. Also, in a centralized regime the total mass of recipients of the subsidy is now 2, i.e. all the individuals in the two countries, rather than 1.

Expressions (1) and (2) highlight a crucial feature of our model: the two regimes affect the variability of consumption through their effects on the variabilty of the tax base and of the tax rate. We now study how these two components of the variability of consumption compare in the two regimes.

\subsection{Decentralized fiscal policy.}

In a decentralized regime, each country decides by majority voting on its own tax rate. Since

and inter-county transfers. 
voting takes place after the shock has occurred, there is no uncertainty at the moment of voting: an agent of type $i$ in country $j$ prefers the tax rate $t^{d}$ that maximizes $C_{i, j}^{d}$ as given in expression (1). The solution to this problem is a linear function of the endowment of individual of type $i$ relative to the average:

$$
t_{i}^{d}=\left\{\begin{array}{cl}
1-\frac{n_{i}}{\bar{n}} & \text { for } n_{i}<\bar{n} \\
0 & \text { for } n_{i} \geq \bar{n}
\end{array}\right.
$$

This result is intuitive. Consider the first order condition of the problem of an individual of type $i$ :

$$
-n_{i}+(1-t) \bar{n}=0
$$

The first term on the l.h.s. is the marginal cost of taxation: this cost is independent of the tax rate, but depends positively on the pre-tax income of an individual. The second term is the marginal benefit of an increase in taxation - i.e., the marginal increase in the subsidy - which decreases with the tax rate because of the convex costs of taxation. It follows that individuals with lower income will vote for a higher tax rate. However, individuals with income above the average always pay more in taxes than they receive as a subsidy. Thus, their preferred tax rate is always $0 .{ }^{7}$

Note an important feature of the solution (3) to the problem of individual $i$. Because the tax rate is chosen after the shock, and the latter affects all individuals in the country in the same proportion, the ratio of individual $i$ 's income to the average income is independent of the shock. Consequently, each agent always prefers the same tax rate irrespective of the realization of the shock.

Because in this model preferences are single-peaked, the policy preferred by the median voter, an individual of type $B$, prevails. Hence, the tax rate adopted in equilibrium is the same in both countries, and remembering that the median voter is an agent of type $B$, it is equal to

$$
t^{d}=1-\frac{n_{B}}{\bar{n}}
$$

There are two important characteristics of the equilibrium fiscal policy in the decentralized regime. On one hand, there is no uncertainty about policy: the tax rate is constant in all states of the world. On the other hand, the subsidy is stochastic because the tax base is; thus, by its nature a decentralized fiscal policy cannot provide any insurance against the only exogenous source of risk in this model, the country-specific shock $\epsilon_{j}$.

\footnotetext{
${ }^{7}$ If there were no deadweight cost of taxation, at any given tax rate an agent with income below the average would pay less in taxes than he would receive as a subsidy, and conversely for an agent with income above the average. Thus, the optimal tax rate would be 1 for any agent poorer than the average, and 0 for any agent richer than the average.
} 


\subsection{Centralized fiscal policy.}

Consider now the voting process of the centralized regime. Individual $i$ in country $j$ prefers the tax rate $t$ that maximizes $C_{i, j}^{c}$ as given in expression (2). Although the tax base is now independent of the shock, the income of individual $i$ still depends on the shock. Thus, and in contrast to the decentralized regime, the tax rate that an individual prefers is now a function of the shock:

$$
t_{i, j}^{c}=\left\{\begin{array}{cc}
1-\frac{n_{i}\left(1+\epsilon_{j}\right)}{\bar{n}\left(1+\left(\epsilon_{1}+\epsilon_{2}\right) / 2\right)} & \text { for } n_{i}\left(1+\epsilon_{j}\right)<\bar{n}\left(1+\left(\epsilon_{1}+\epsilon_{2}\right) / 2\right) \\
0 & \text { for } n_{i}\left(1+\epsilon_{j}\right) \geq \bar{n}\left(1+\left(\epsilon_{1}+\epsilon_{2}\right) / 2\right)
\end{array}\right.
$$

The tax rate that prevails in the voting process is the one preferred by the individual with median pre-tax income in the combined population of the two countries. Who exactly this individual will be depends on the specific assumption one makes on the shape of the distribution of endowments, an issue that we explore in sections 5 and 6 below. However, one point is already clear from (6): in general, and in contrast to the decentralized regime, the tax rate in the centralized regime is stochastic, that is, it depends on the realization of the shock.

We can further clarify the difference between the two regimes, while at the same time greatly simplifying the analysis of this case, by making the assumption that the productivity shocks in the two countries are perfectly negatively correlated: $\epsilon_{1}=-\epsilon_{2}$. Under this assumption the tax base in the centralized regime becomes deterministic and equal to $2 \bar{n}$, since:

$$
\bar{n}\left(1+\epsilon_{1}\right)+\bar{n}\left(1+\epsilon_{2}\right)=\bar{n}\left(1+\epsilon_{1}\right)+\bar{n}\left(1-\epsilon_{1}\right)=2 \bar{n}
$$

The assumption of perfect negative correlation between $\epsilon_{1}$ and $\epsilon_{2}$ is clearly extreme, and much stronger than we need in order to develop our argument. Its first advantage has to do with analytical tractability. As we have shown above, the tax rate resulting from the voting process is a function of the ratio of the median income to the average income. Our assumption then means that the denominator of this ratio in a centralized regime is always constant. This avoids having to deal with the ratio of two random variables, and greatly facilitates the analysis of the model.

The second advantage of this assumption is that it highlights in a stark way the main differences between the decentralized and the centralized regime. Under this assumption the tax base in the centralized regime is constant, while the tax rate is stochastic. Hence, the centralized regime has opposite characteristics to the decentralized regime: it has no uncertainty on the tax base, but a higher uncertainty on the policy instrument. 


\section{Economic risk and political risk.}

The difference in the expected utility in the two regimes, $E\left(U^{d}\left(t^{d}\right)\right)-E\left(U^{c}\left(t^{c}\right)\right)$, can be decomposed into three main components, each with an intuitive interpretation: ${ }^{8}$

$$
\begin{aligned}
E\left(U^{d}\left(t^{d}\right)\right)-E\left(U^{c}\left(t^{c}\right)\right)= & {\left[E\left(U^{d}\left(\bar{t}^{d}\right)\right)-E\left(U^{c}\left(\bar{t}^{d}\right)\right)\right]+} \\
& {\left[\left[E\left(U^{d}\left(t^{d}\right)\right)-E\left(U^{d}\left(\bar{t}^{d}\right)\right)\right]+\left[E\left(U^{c}\left(\bar{t}^{c}\right)\right)-E\left(U^{c}\left(t^{c}\right)\right)\right]\right]+} \\
& {\left[E\left(U^{c}\left(\bar{t}^{d}\right)\right)-E\left(U^{c}\left(\bar{t}^{c}\right)\right)\right] }
\end{aligned}
$$

For future reference, note that a positive value of the expected utility differential means that an individual is better off in the decentralized regime.

Consider the first component of (8). This component is equal to the difference in utility between the two regimes when the tax rate is held constant at its expected value in the decentralized regime, $\bar{t}^{d}$ (note that in this model $t^{d}=\bar{t}^{d}$ since $t^{d}$ is always constant; however, conceptually it is useful to distinguish between the two tax rates.) At this tax rate, the expected value of consumption is the same in the two regimes, but the variance is higher in the decentralized regime because the tax base is more variable. Therefore, the first component of our decomposition, $E\left(U^{d}\left(\bar{t}^{d}\right)\right)-E\left(U^{c}\left(\bar{t}^{d}\right)\right)$, is negative and captures the difference between the two regimes that can be attributed to the different variability of their tax bases. We call this term the economic risk utility differential.

The second component captures the effects of different patterns of variation of the tax rate in the two regimes about their expected values. This component can be written as $\left[E\left(U^{d}\left(t^{d}\right)\right)-E\left(U^{d}\left(\bar{t}^{d}\right)\right)\right]-\left[E\left(U^{c}\left(t^{c}\right)\right)-E\left(U^{c}\left(\bar{t}^{c}\right)\right)\right]$, where $\bar{t}^{c}$ is the expected tax rate in the centralized regime. Clearly, the first term in brackets in this expression is 0 , since in the decentralized regime the equilibrium tax rate is constant. What is left in the expression then captures the fact that the higher diversity of voters in the centralized regime leads to a more variable tax rate than in the decentralized regime. Therefore, we call this component the political risk utility differential. Note that this component can be positive or negative, depending on the covariance of $t^{c}$ with the income of an individual.

Finally, the third component, $E\left(U^{c}\left(\bar{t}^{d}\right)\right)-E\left(U^{c}\left(\bar{t}^{c}\right)\right)$, captures the effects of systematic differences in the fiscal policies of the two countries. These can arise for instance because the median voters are different in the two regimes, and therefore the average tax rates that they prefer are different. Because different average degrees of redistributions are associated with different average tax rates, this component will be positive or negative, depending on

\footnotetext{
${ }^{8}$ For notational convenience, we drop the indices $i$ and $j$ from the expressions for the expected utilities.
} 
the pre-tax income of an individual. We call this component the systematic fiscal policy utility differential.

To summarize, and recalling that $t^{d}=\bar{t}^{d}$, we can define each of the three terms on the r.h.s of (8) according to the following

\section{Definition 2.}

\section{We define:}

(i) $E\left(U^{d}\left(t^{d}\right)\right)-E\left(U^{c}\left(t^{d}\right)\right)$ as the economic risk utility differential of the two regimes;

(ii) $E\left(U^{c}\left(\bar{t}^{c}\right)\right)-E\left(U^{c}\left(t^{c}\right)\right)$ as the political risk utility differential of the two regimes;

(iii) $E\left(U^{c}\left(\bar{t}^{d}\right)\right)-E\left(U^{c}\left(\bar{t}^{c}\right)\right)$ as the systematic fiscal policy utility differential of the two regimes.

The traditional argument that a centralized fiscal policy allows some form of insurance against country-specific shocks (as in Sachs and Sala-I-Martin (1992)) is implicitly based on the first item in our decompositions (8). In other words, the argument only considers the relative economic risk of the two regimes by comparing them at the same tax rate. The point of what follows is to show that, when one considers the other components, and in particular the political risk component, the results concerning the relative merits of centralization and decentralization may change drastically.

Our point is particularly clear in those regions of parameter values such that

$$
E\left(U^{d}\left(t^{d}\right)\right)-E\left(U^{c}\left(t^{c}\right)\right)>0
$$

and

$$
E\left(U^{d}\left(t^{d}\right)\right)-E\left(U^{c}\left(\bar{t}^{c}\right)\right)<0
$$

In other words, suppose that the total utility differential (the l.h.s. of (9)) is positive, but the sum of the economic risk utility differential and of the systematic utility differential (the l.h.s. of (10)) is negative. This implies that the individual prefers the decentralized regime (inequality (9)), but would prefer the centralized regime if the centralized tax rate did not vary about its expected value, that is, if there were no political risk (inequality (10). In other words, the only reason why the individual prefers the decentralized regime is that the political risk is higher in the centralized regime, and this more than compensates for the effects of the other two factors.

Our main results are summarized in Definition 3 and Propositions 1 and 2 below:

\section{Definition 3:}

For any given $n_{B}$, a polarized distribution is characterized by a large distance between $n_{A}$ 
and $n_{C}$.

Notice that, according to Definition 3, an increase in polarization, holding constant $n_{B}$, corresponds to a mean- and median-preserving spread.

\section{Proposition 1:}

For a wide range of parameters of the distribution of income, a majority of individuals in each country prefer the decentralized regime only because of the higher political risk of the centralized regime.

\section{Proposition 2:}

The more polarized is the distribution of income, the more likely it is that a majority of agents in each country prefer the decentralized regime because of the higher political risk in the centralized regime.

Thus, Proposition 1 states that on a wide range of parameter values both inequalities (9) and (10) are realized for a majority of individuals in each country. Because of the endogeneity of the policy instrument, the centralized regime might not be able to fulfill any insurance role. The "political risk", namely the additional variability of the policy instrument in the centralized regime, for some parameter values more than compensates for the reduction in the "economic risk", namely the reduction in the variablity of the tax base in the centralized regime. According to Proposition 2, a highly polarized distribution of income leads to high uncertainty over the policy instrument in the centralized regime, and therefore tips the balance in favor of the decentralized regime.

Proposition 1 leads directly to the following corollary:

\section{Corollary 1:}

For a wide range of parameter values, at least one country will veto a centralized fiscal policy regime because of its higher political risk.

Note that in our model a decentralized regime would emerge under a much wider range of parameters than described by Proposition 1. Specifically, whenever inequality (9) is realized for a majority of agents in at least 1 country, the centralized regime is not feasible, regardless of the sign of inequality (10). Because the role of the systematic utility differential is well understood, we focus here on the case considered in Proposition 1 in order to better highlight the role of the political risk.

We illustrate Propositions 1 and 2 under two different sets assumptions. First, in the 
next section we consider the case of equal expected equilibrium tax rates in the two regimes. This allows us to provide an analytical solution to the model when the utility function is quadratic. The obvious disadvantage of this approach is that quadratic utility functions display increasing absolute risk aversion, a rather unappealing property. In section 6 we consider the more general case that does not impose any condition on the equilibrium tax rate, assuming a constant relative risk aversion utility function. Now, however, despite the "stripped-down" formalization of the model, we have to resort to numerical solutions.

\section{Quadratic utility with equal expected tax rates.}

We first consider the case when, in equilibrium, the average tax rates in the two regimes are equal: $\bar{t}^{d}=\bar{t}^{c}$ The analysis of this case allows us to isolate most clearly the fundamental trade-off between the two regimes. In fact, under this assumption the systematic fiscal policy utility differential is zero. From Definition 3, any difference in their expected utility can then be attributed entirely to the relative importance of the economic risk and of the political risk. In other words, under the assumption of equal expected tax rates between the two regimes inequality $(10)$ is always satisfied, since its 1.h.s. represents the economic risk utility differential only. We know that the economic risk utility differential is always negative: if the tax rate were fixed at its common average value, every individual would certainly prefer the centralized regime. Therefore, if inequality (9) is realized and the individual prefers the decentralized regime, necessarily this must be because of the higher political risk in the centralized regime., i.e. because the policy instrument is more unpredictable. We study precisely under what conditions a majority of agents, either in the total population of the two countries or in each country, prefer the decentralized regime.

For simplicity, and without loss of generality, we assume that the shock $\epsilon$ can take only two values, $x$ and $-x$, each with probability .5 . It follows that there is only one possible configuration of parameters that deliver the condition of equality of the expected tax rates in the two regimes:

$$
\begin{aligned}
& \text { (a) } n_{A}(1+x)<n_{B}(1-x), n_{B}(1+x)<n_{C}(1-x) \\
& \text { (b) } n_{B}(1+x)<\bar{n}
\end{aligned}
$$

This condition has a rather intuitive interpretation. Part $(a)$ implies that the relative position of any two income groups in different countries is independent of the shock: for instance, when the shock is negative in country 1 and positive in country 2 , the income of a member of group B in country 1 is still higher than the income of a member of group $A$ in country 2. This ensures that the median voter in the centralized regime is always a member 
of group B in country 1, the larger country (obviously we could rewrite the conditions to make the median voter a member of group $B$ in country 2). Part (b) requires that the tax rate proposed by the median voter is never 0 . As we show below, this ensures that the tax rates proposed by the median voter in the centralized regime under the two realizations of the shock are symmetric about the decentralized tax rate, so that their average is exactly the decentralized tax rate.

Because the median voter is always a member of group B in country 1, and preferences are still single-peaked, the tax rate adopted in equilibrium, $t^{c}$, is now:

$$
t^{c}=1-\frac{n_{B}\left(1+\epsilon_{1}\right)}{\bar{n}}
$$

(Recall that we have assumed for simplicity $\epsilon_{1}=-\epsilon_{2}$, so that the per capita income of the economies combined that appears at the denominator of (12) is always constant at $\bar{n}$ ). The crucial result here is that the equilibrium tax rate is no longer constant: it covaries negatively with the shock in country 1 . In fact, when $\epsilon_{1}$ is positive (resp. negative), the income of the median voter, $n_{B}\left(1+\epsilon_{1}\right)$, is high (resp. low), while as we know the average income of the two countries remains constant; thus, from (6), the tax rate preferred by the median voter is low (resp. high). On the other hand, the tax base is constant. Thus, in these two respects the centralized regime is exactly the opposite of the decentralized regime. In addition, as we required at the beginning, the expected value of the tax rate is the same in the two regimes.

Assume now that individuals maximize a utility function of the type:

$$
U\left(C_{i, j}\right)=\alpha C_{i, j}-C_{i, j}^{2}
$$

We present the main intuition behind Propositions 1 and 2, leaving the formal analytical solution to the Appendix. We do so by considering the expected utility of each type of individual in each country as a function of the parameters of the distribution of income. For notational simplicity, and without loss of generality, from now on we normalize the average income of the economy, $\bar{n}$, to 1 .

Type-A individuals, country 1 .

Consider first individuals of type $A$ for the case of $n_{A}=0$. These agents prefer the decentralized regime for the more realistic values of $n_{B}$. The intuition is as follows. As we know, the economic risk utility differential is negative: ${ }^{9}$ when the tax rate is constant at the common expected value, clearly $E\left(U^{d}\left(t^{d}\right)\right)<E\left(U^{c}\left(t^{d}\right)\right)$; on the other hand, the political

\footnotetext{
${ }^{9}$ Once again, recall that a "positive" differential indicates that the decentralized regime gives a higher expected utility, and a "negative" differential that the centralized regime gives a higher expected utility.
} 
risk utility differential is unambigously positive: $E\left(U^{c}\left(\bar{t}^{c}\right)\right)>E\left(U^{c}\left(t^{c}\right)\right)$ since the expected value of the subsidy in the centralized regime is higher and the variance is lower when the tax rate is constant at $\bar{t}^{c}$ than when it depends on the shock.

The economic and political risk utility differentials therefore have opposite signs. To determine the sign of the overall utility differential, consider the variance and the expected value of the subsidy. Let $s^{c}$ and $s_{j}^{d}$ be the subsidy in the centralized and decentralized regimes, respectively. Some simple algebra shows that the expected value of the subsidy is always higher in the decentralized regime:

$$
E\left(s_{j}^{d}\right)>E\left(s^{c}\right)
$$

which simply reflects the fact that the increased variability of the tax rate in the centralized regime leads to higher deadweight losses. On the other hand, the variance of the subsidy in the two regimes depends on the value of $n_{B}$ :

$$
\operatorname{Var}\left(s^{c}\right)>\operatorname{Var}\left(s_{j}^{d}\right) \Longleftrightarrow 3 n_{B}^{4}+2 n_{B}^{2}-1>0
$$

Thus, the variance of the subsidy is higher in the centralized regime when $n_{B}>1 / 9$, and it is higher in the decentralized regime when $n_{B}<1 / 9$.

Therefore, when $n_{B}>1 / 9$ (the more realistic case), in the decentralized regime both the expected value of the subsidy is higher and its variance is lower. Conversely, when $n_{B}$ is below $1 / 9$, the variance of the subsidy is higher in the decentralized regime. Hence, for all values of $n_{B}$ higher than a certain value $n_{B_{1}}$ (which in turn is less than 1/9), in both countries members of group $A$ with no labor endowment prefer the decentralized regime.

As the endowment of poor agents increases from 0 , the importance of the subsidy as a source of consumption decreases while that of the after-tax earned income increases. As their endowment increases, individuals of type $A$ in country 1 will be increasingly better off in the centralized regime, because the tax rate is countercyclical there and applies to a positive pre-tax income. Therefore, for any given $n_{B}$ individuals of type $A$ with endowment lower than a certain value of $n_{A}$ will prefer the decentralized regime in country 1 .

Type-A individuals, country 2.

Since the tax rate in the centralized regime is procyclical in country 2 , poor agents in country 2 will prefer the decentralized regime for an even wider range of values of $n_{A}$. In fact, this is a general feature of the model: it can be shown that the range of parameter values such that individuals of any given type prefer the decentralized regime in country 1 is a subset of the same range in country 2 . This is a consequence of the fact that the median voter is always in country 1 . Thus, taxes are countercyclical in country 1 and procyclical in country 2 . 
In conclusion, there is a wide range of configurations of the distribution of income, characterized by high values of $n_{B}$ and low values of $n_{A}$, such that individuals of type $A$ in both countries prefer the decentralized regime. In addition, this range is larger in country 2.

Type-B individuals, country 1.

Individuals of type B in country 1 always prefer the centralized regime: indeed, they are always the decisive voters and therefore cannot do worse in the centralized regime, which has the same expected tax base but a lower variance.

\section{Type-B individuals, country 2.}

In contrast to individuals of type $B$ in country 1 , and for the reasons mentioned above individuals of type $B$ in country 2 are better off in the decentralized regime for a wide range of parameter values, again characterized by high values of $n_{B}$.

Type-C individuals, country 1.

Individuals of type $\mathrm{C}$ too are better off in the decentralized regime in a region characterized by high values of $n_{B}$ and low values of $n_{A}$. The intuition is as follows. Using the expressions for the equilibrium tax rates, in the decentralized regime the after-tax earned income is $\left(1+\epsilon_{1}\right) n_{C} n_{B}$, while in the centralized regime it is $\left(1+\epsilon_{1}\right)^{2} n_{C} n_{B} .{ }^{10}$ Therefore, in the centralized regime the expected value of the after-tax earned income is larger, but on the other hand its variance is four times as large. Because with quadratic utility risk aversion increases with the level of consumption, i.e. with $n_{B}$ and $n_{C}$, the higher $n_{C}$ and $n_{B}$ (therefore, the lower $n_{A}$ and the higher $n_{B}$ ), the better off an individual of type $C$ will be in the decentralized regime. ${ }^{11}$

Type-C individuals, country 2.

In country 2 there are two basic differences. First, now the after-tax earned incomes are $\left(1+\epsilon_{2}\right) n_{C} n_{B}$ in the decentralized regime and $\left(1-x^{2}\right) n_{C} n_{B}$ in the centralized regime. ${ }^{12}$ Hence, the expected value of the after-tax earned income is now higher in the decentralized

\footnotetext{
${ }^{10}$ The expression for the decentralized regime can be obtained by substituting the decentralized tax rate, $t^{d}=\left(1-n_{B} / \bar{n}\right)$, into the expreasion for the after-tax earned income, $\left(1+\epsilon_{1}\right) n_{C}(1-t)$. The expression for the centralized regime can be obained similarly, using the formula for the centralized tax rate, $t^{c}=\left(1-n_{B}\left(1+\epsilon_{1}\right) / \bar{n}\right)$.

${ }^{11}$ Increasing absolute risk aversion is a rather unappealing property of the quadratic utility function. However, our results do not hinge on this feature. In fact, in the next section we show that all our results still go through when the utility function exhibits constant relative risk aversion.

${ }^{12}$ The after-tax earned income in the centralized regime is $n_{C}\left(1+\epsilon_{2}\right)\left(1-t^{c}\right)$. From $t^{c}=1-n_{B}\left(1+\epsilon_{1}\right)$ and $\epsilon_{1}=-\epsilon_{2}$ one obtains the expression $\left(1-x^{2}\right) n_{B} n_{C}$ in the text.
} 
regime, but its variance too is higher. Second, as usual the cyclical behavior of the tax rate is more unfavourable in the centralized regime. As it turns out, this second effect more than offsets the effects of the higher variance of the after-tax earned income in the decentralized regime; as a result, individuals $C$ in country 2 are better off in the decentralized regime for an even larger range of parameters than in country 1 . Thus, individuals of type $\mathrm{C}$ in both countries are better off in the decentralized regime for configurations of income distribution characterized by high values of $n_{B}$ and low values of $n_{A}$ (i.e., high values of $n_{B}$ and of $n_{C}$ ).

In conclusion, as stated in Proposition 1, there is a range of values of the parameters of income distribution where a majority of individuals in each country (individuals of type $A$ and $C$ in country 1 and all individuals in country 2) are better off in the decentralized regime. Note that, for an even wider range of parameters, a majority of individuals in country 2 will be better off in the decentralized regime and therefore will veto a centralized regime. Furthermore, the result is not an artifact of the assumption that the median voter is always in the same country. In fact, even a majority in country 1 , where the median voter resides, prefer the decentralized regime for a wide range of parameter values. Proposition 2 also is clearly verified, since a decentralized regime prevails in a region characterized by a highly polarized distribution (low values of $n_{A}$ and therefore high values of $n_{C}$ ).

In addition, in this model where the expected tax rates are the same in the two regimes, the higher variability of the tax rate in the centralized regime unambigously reduces the expected value of aggregate consumption by increasing the expected value of the costs of collecting or redistributing taxes. In this sense, therefore, the centralized regime also introduces an element of inefficiency relative to the decentralized regime:

\section{Proposition 3:}

In the centralized regime the expected aggregate consumption is lower, because the expected value of distortions is higher.

Proof:

Recalling that the average endowment in each economy is 1 by normalization, the aggregate consumption of the two countries in each regime is $2\left[1-t^{i}+\left(t^{i}-\frac{1}{2} t^{i^{2}}\right)\right]=2\left[1-\frac{1}{2} t^{i^{2}}\right]$, $i=d$, c. Because the average tax rates are the same in the two regimes but the variance is higher in the centralized regime, the result follows immediately.

Thus, Proposition 3 highlights a sort of consumption inefficiency of the centralized regime. It is important to note that the centralized regime is Pareto efficient, since for instance agents $B$ in country 1 are better off than in the decentralized regime. The criterion of efficiency emphasized in Proposition 3 is therefore exclusively one of expected aggregate 
consumption. In this model where labor supply is inelastic, taxation does not distort the allocation of the productive factors; however, it still distorts the economy by affecting the costs of collecting or redistributing taxes.

\section{The more general case.}

We now study our model without imposing the restricition that the average tax rates be the same in the two regimes. This implies that all three components of the expected utility differential in Definition 2 can now be non-zero. In addition, because the quadratic utility function we used in the previous section has rather unattractive properties regarding risk aversion, we now assume that individuals have a constant relative risk aversion (CRRA) utility function of the form:

$$
U_{i, j}=\frac{C_{i, j}^{1-\gamma}}{1-\gamma} ; \quad \gamma>0
$$

where $\gamma$ is the coefficient of relative risk aversion. Another avantage of this utility function is that it allows us to study the role of risk aversion.

With this utility function, in general it is not possible to solve our model analytically. We display the results of some numerical solutions under different parameter values in Figures 1 and 2. Each panel refers to a different income group, and plots the total utility differential $E\left(U^{d}\left(t^{d}\right)\right)-E\left(U^{c}\left(t^{c}\right)\right)$ (solid line) and the part that is left after subtracting the political-risk differential, $E\left(U^{d}\left(t^{d}\right)\right)-E\left(U^{c}\left(\bar{t}^{c}\right)\right)$ (broken line), both as functions of the coefficient of relative risk aversion, $\gamma$, starting from a value of $\gamma$ equal to 1 (the logarithmic case). Both differences are expressed in percentage terms. Whenever the solid line is above the horizontal axis, inequality (9) above is realized: the total expected utility differential is positive and the individual prefers the decentralized regime. Whenever the broken line is below the horizontal axis, inequality (10) above is realized: the individual would prefer the centralized regime if it had no political risk, i.e. if the centralized tax rate were constant. In each panel, the area between two heavy vertical lines marks the range of values of the coefficient of relative risk aversion where the two inequalities are simultaneously realized for that particular agent.

In the numerical solutions displayed in Figures 1 and 2 we assume a value of $n_{B}$ equal to .8. This generates an average tax rate in the decentralized regime of .2 , close to the average income tax rate in many industrialized countries. As usual, in each country the average endowment $\bar{n}$ is 1 and each group has exactly one third of the total population. The difference between the two figures is that in Figure 1 the distribution of endowments is highly polarized $\left(n_{B}=.8, n_{A}=.1\right)$, while in Figure 2 it is very equal $\left(n_{B}=.8, n_{A}=.7\right)$. 
We also assume that the country-specific shock can take more than two values: $.05, .10, .15$ and their opposites, each with probability $1 / 6$, so that the expected value of the shock in each country is 0 . The shocks in the two countries are still perfectly negatively correlated.

Figure 1, which refers to a highly polarized distribution of endowments, illustrates Proposition 1: on a very wide range of values of $\gamma$ both inequalities (9) and (10) are satisfied, namely a majority of individuals prefer the decentralized regime solely because of the highre political risk of the centralized regime. A comparison of Figure 1 with Figure 2, that represents a less polarized distribution of income, illustrates Proposition 2: the range of parameter values for which a majority of individuals prefer the decentralized regime is increasing in the polarization of income distribution.

The main intuition behind the six panels of Figures 1 and 2 is very similar to that for the case of quadratic utility function. Accordingly, here we will limit our comments to the new insights provided by the analysis of a CRRA utility function. Also, for the sake of brevity, we will only consider Figure 1. First, note that the broken line is always sloping downward: as risk aversion increases, all individuals value more and more the lower economic risk in the centralized regime. Second, for individuals of type A the solid line always slopes upward: as risk aversion increases, poor individuals, for whom the subsidy is a major component of income, increasingly dislike the higher variance of the subsidy in the centralized regime (see inequality (15)). Third, only for the median voter (individuals of type B in country 1) is the broken line above the solid line: the median voter could always choose to decrease the variability of the centralized tax rate by proposing a constant tax rate. If he does not do that, it must be the case that he benefits from it. Fourth, individuals of type $\mathrm{C}$ in country 1 increasingly dislike the centralized regime as risk aversion increases (the solid line is sloping upward): in fact, the centralized regime exacerbates the variance of their pre-tax income, as the tax rate is high when income is low and low ehen income is high. Fifth, for symmetric reasons individuals of type $\mathrm{C}$ in country 2 dislike the decentralized regime less and less as risk aversion increases (the solid line is sloping downward): it is true that the centralized regime introduces political risk, but it also helps smooth differences in the pre-tax income since the centralized tax rate now covaries positively with income. As risk aversion increases, individuals of type $C$ in country 2 appreciate more and more this second effect of the centralized regime.

It is important to emphasize once again that our main results are due exclusively to the fact that the variability of the policy instrument, the tax rate, increases when one moves from the decentralized to the centralized regime. If the tax rate remained constant at its expected value, a large majority of agents in each country would always be better off in the centralized regime. However, because the tax rate is determined endogenously in this model, it is not possible to constrain it not to move with the shock in the centralized 
regime.

\section{Conclusions.}

Some regions of the world, like Western Europe, are going through a process of increasing political and economic integration, while others, like Eastern Europe, are experiencing a strong tendency towards fragmentation. Furthermore, within individual countries there are strong movements of opinion in favor of more involvement of the central government in redistribution (e.g., the United States) or towards a decentralization of fiscal policy (e.g., Italy).

These movements in opposite direction suggest the existence of a basic trade-off. Fiscal integration in large political jurisdictions has its advantages: for example, economies of scale in the provision of public goods and the possibility of mutual insurance, which is the point emphasized in our paper. ${ }^{13}$ On the other hand, integration comes at a cost. The most general way of capturing this cost is the idea that, when the size of a political jurisdiction increases, policy becomes more uncertain because the outcome results from the aggregation of preferences of a more diverse population. The larger and more heterogeneous the political jurisdiction, the higher are these costs.

The particular type of heterogeneity that we have emphasized in this paper is generated by different realizations of the shock in different parts of the political jurisdictions, which gives rise to differences in the desired level of redistribution. Thus, this paper points out some drawbacks of excessive integration. In particular, it questions the generality of the almost universally accepted view that, at least for insurance purposes, a centralized fiscal system is superior to a decentralized one.

As we mentioned in the introduction, we believe that the basic idea of this paper extends beyond the specific case we have analysed. Expressed in more colorful terms than we used so far, this basic idea is that political integration, beyond the establishment of a free-trade regime, might backfire as the participating countries discover that they cannot agree on important common policies. The case of European integration is, perhaps, a good example. Supporters have often emphasized its economic benefits. Skeptics often mention the risk associated with integrating countries with important politico-economic differences. The point of this paper is, hopefully, to clarify in a unified framework the trade-off leading to these conflicting views.

The voting mechanism that we have assumed is a very simple one, implying a direct

\footnotetext{
${ }^{13}$ For a discussion of economies of scale in the provision of public goods and their effects on the optimal size of countries with heterogeneous individuals, see Alesina and Spolaore (1994).
} 
vote on the tax rate in the union. However, it is conceivable that certain voting rules may be more effective than others in reducing (or eliminating) the political risk inherent in the centralized regime while at the same time allowing the participants to enjoy the advantages, in terms of reduced economic risk, of that regime. ${ }^{14}$ The next step therefore consists in studying how different voting rules may improve upon the trade-off between economic and political risk that we have emphasized in this paper.

${ }^{14}$ For a discussion of the properties of different voting mechanisms in the context of monetary policy in the European Union, see Alesina and Grilli (1991). 


\section{Appendix.}

We now prove Proposition 1 for the case of a quadratic utility function and equal expected tax rates in the two regimes:

$$
U=\alpha C-C^{2}
$$

Recall that all income groups have the same share of the total population in each country: $p_{i}=1 / 3 \forall i$. The highest possible income of an agent of type $\mathrm{C}$ then is $n_{C}=3$, which occurs when $n_{A}=n_{B}=0 . \alpha \geq 6$ is therefore a necessary condition for the first derivative of the utility function to be positive for all possible configurations of the distribution of income. Again to simplify the exposition, in what follows we assume that $\alpha=6$. Also, in country 1 the total mass of the population is infinitesimally higher than in country 2 , so that the median voter is always a member of group B in country 1 .

Now let $\Delta_{i}$ be the difference between the expected utility in the decentralized regime and the expected utility in the centralized regime for an indivdual of type $i$ in country 1. Using the equilibrium values of the tax rates in the two regimes, we can write:

$$
\Delta_{i}=x^{2}\left[3 n_{B}^{2}-6 n_{i} n_{B}+5 n_{i}^{2} n_{B}^{2}+\frac{5}{4} n_{B}^{4}-5 n_{i} n_{B}^{3}-\frac{1}{4}+x^{2}\left(n_{i}^{2} n_{B}^{2}+\frac{1}{4} n_{B}^{4}+n_{i} n_{B}^{3}\right)\right]
$$

Whenever $\Delta_{i}$ is positive, an agent of type $i$ prefers the decentralized regime. To simplify the analysis, in (A.2) we ignore the terms multiplied by $x^{4}$. Note that consideration of these terms would increase the region where each type of agents prefers the decentralized regime, as all these terms are positive.

Consider first individuals of type $A$ in country 1 . Some simple but tedious algebra establishes the following properties of $\Delta_{A}$ : (i) $\Delta_{A}\left(n_{A}=0\right)>0$ for $n_{B}>n_{B_{1}}$; (ii) $\Delta_{A}\left(n_{A}=\right.$ $\left.n_{B}\right)<0$ always; (iii) $\Delta_{A}\left(n_{B}=1\right)>0$ for $n_{A}<n_{A_{1}}$; (iv) $\partial \Delta_{A} / \partial n_{A}<0$ always. These properties of $\Delta_{A}$ imply that in a region characterized by high values of $n_{B}$ and low values of $n_{A} \Delta_{A}$ is positive.

As we already know, individuals of type $B$ in country 1 always prefer the centralized regime because they are the decisive voters and the tax base is less variable there.

Finally, consider individuals of type $\mathrm{C}$ in country 1 . Substituting $n_{C}=3-n_{B}-n_{A}$ for $n_{i}$ in (A.1), one obtains the following properties for $\Delta_{C}$ : (i) $\Delta_{C}\left(n_{A}=0\right)>0$ for $n_{B}>$ $n_{B_{2}}$; (ii) $\Delta_{C}\left(n_{A}=n_{B}\right)<0$ always; (iii) $\Delta_{C}\left(n_{B}=1\right)>0$ for $n_{A}<n_{A_{2}}$; (iv) $\partial \Delta_{C} / \partial n_{A}$ is increasing in $n_{A}$.

(ii) and (iv) together imply that $\partial \Delta_{C} / \partial n_{A}$ must always be negative for all $n_{B} \geq n_{B_{2}}$. Hence, for any given $n_{B} \geq n_{B_{2}}, \Delta_{C}$ starts out positive for low values of $n_{A}$ and then becomes negative. This establishes that, for agents of type $C$ too, $\Delta_{C}$ is positive in a region characterized by low values of $n_{A}$ and high values of $n_{B}$. 
A similar method can be utilized to show that all agents in country 2 (including agents of type B) prefer the decentralized regime in a region around $n_{A}=0$ and $n_{B}=1$. In fact, for each type of agent this region is larger than for the same type of agent in country 1 . 


\section{References.}

Alesina, A. and V. Grilli (1991): "The European Central Bank: Reshaping Monetary Politics in Europe", in: M. Canzoneri, P. Masson and V. Grilli (eds.): Establishing a Central Bank: Issues in Europe and Lessons from the U.S., London, Cambridge University Press; Alesina, A. and E. Spolaore (1994): "On the Number and Size of Nations", mimeo, Harvard University;

Brown, C. and W. Oates (1987): "Assistance to the Poor in a Federal System", Journal of Public Economics, 32, 307-330;

Gordon, R.H. (1983): "An Optimal Taxation Approach to Fiscal Federalism" Quarterly Journal of Economics, 97, 567-586;

Ladd, H.F. and F.C. Doolittle (1982): "Which Level of Government Should Assist the Poor?", National Tax Journal 35, 323-36;

Meltzer, A. H. and S. F. Richard (1981): "A Rational Theory of the Size of Government", Journal of Political Economy, 89, 914-27;

Pauli, M.V. (1973): "Income Redistribution as a Local Public Good", Journal of Public Economics 2, 35-58;

Perotti, R. (1993): "The Political Economy of Income Redistribution in a Federal System", manuscript, Harvard University;

Persson, T. and G. Tabellini (1992): "Federal Fiscal Constitutions. Part 1: Risk Sharing and Moral Hazard", CEPR Working Paper No. 728, October;

Roberts, K.W.S. (1977): "Voting Over Income Tax Schedules", Journal of Public Economics, 18, 329-40;

Romer, T. (1975): "Individual Welfare, Majority Voting, and the Properties of a Linear Income Tax", Journal of Public Economics, 14 163-85;

Sachs, J. and X. Sala-I-Martin (1992): "Fiscal Federalism and Optimum Currency Areas: Evidence for Europe from the United States", in: M. Canzoneri, P. Masson and V. Grilli (eds.): Establishing a Central Bank: Issues in Europe and Lessons from the U.S., London, Cambridge University Press; 
FIGURE 1
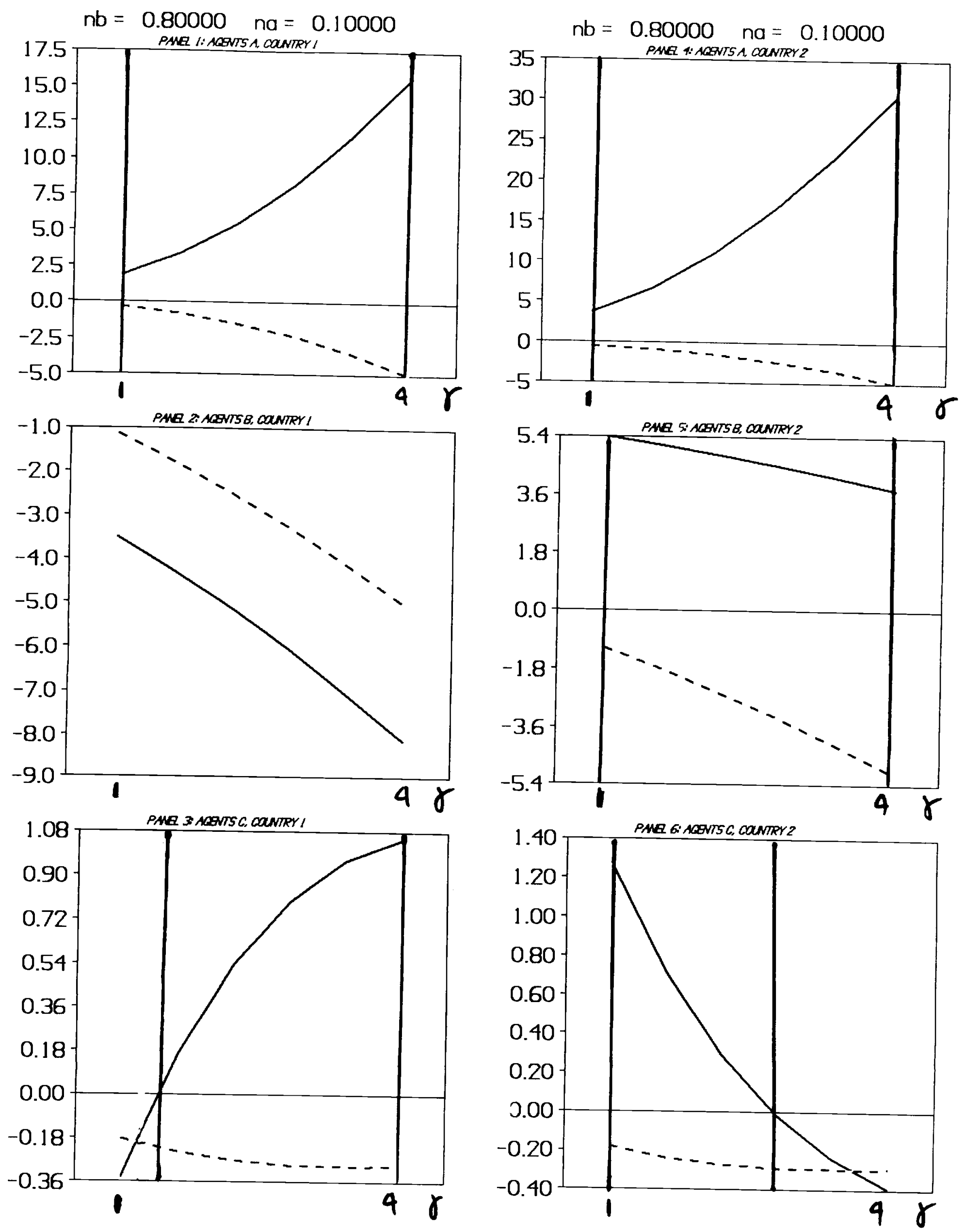


\section{FIGURE 2}
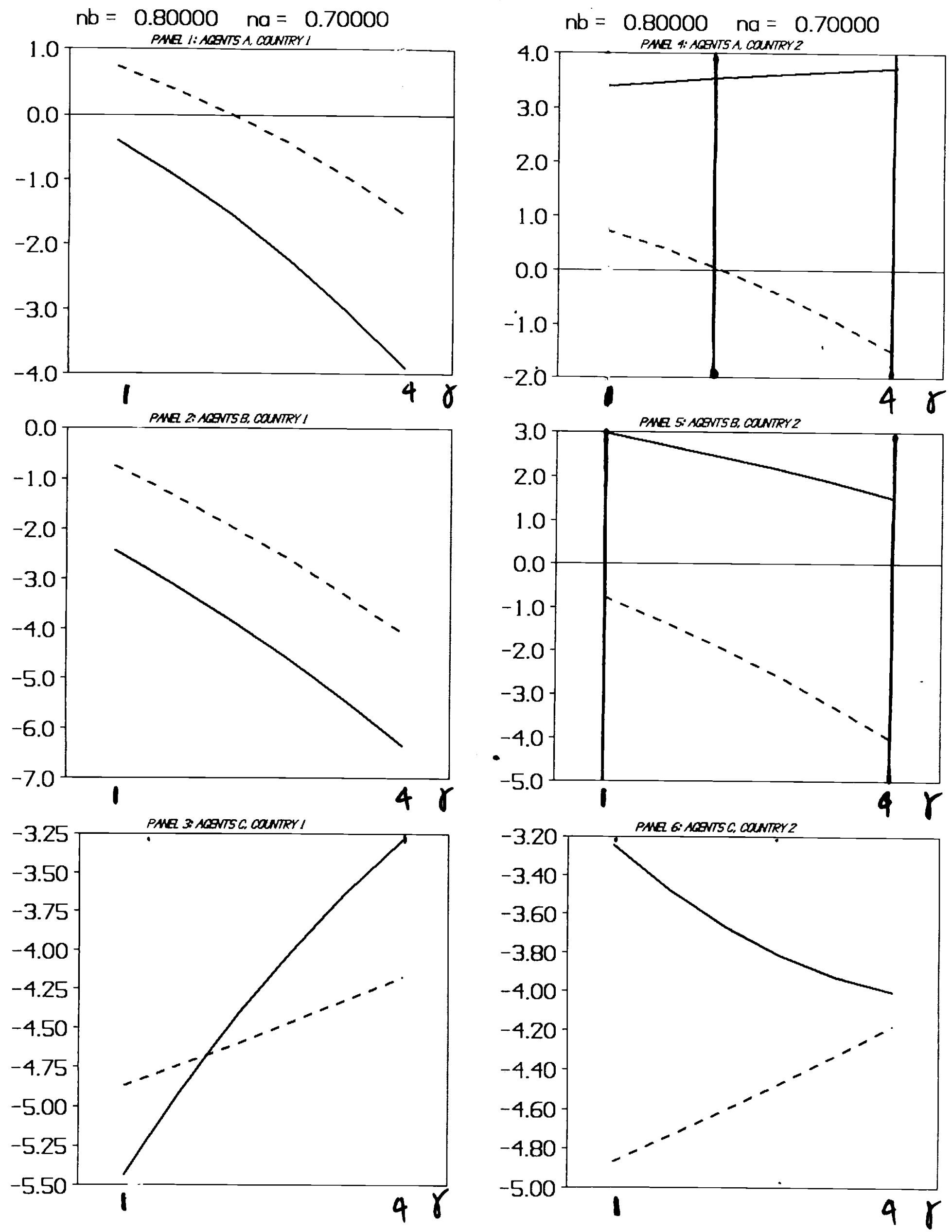